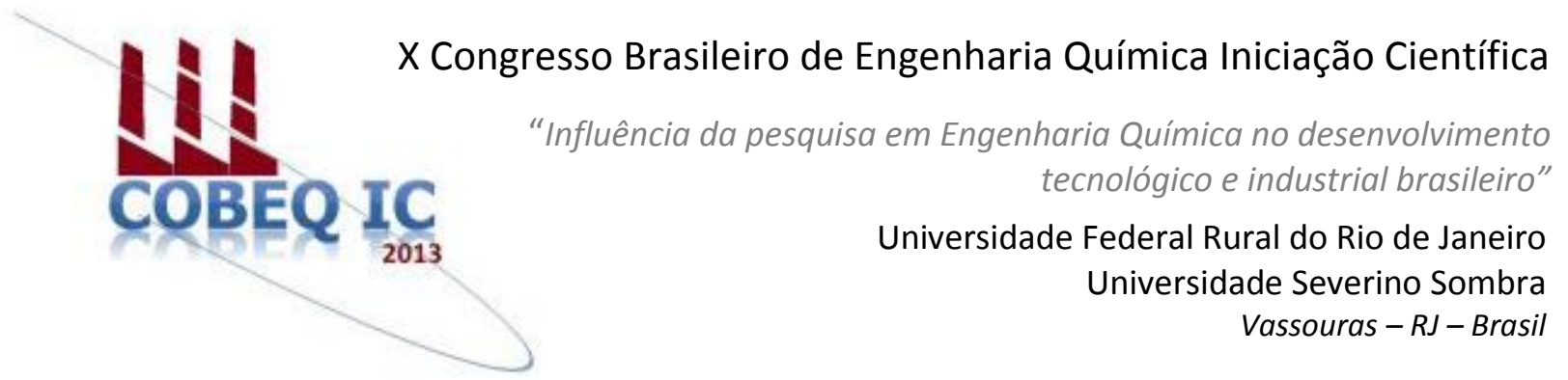

\title{
PRODUÇÃO DE XILITOL E ETANOL A PARTIR DE HIDROLIZADO ENZIMÁTICO DE BAGAÇO DE CAJU
}

\author{
GOMES $^{* 1}$, S. D. L.; ALBUQUERQUE ${ }^{2}$, T. L.; JUNIOR ${ }^{1}$, J. E. M.; GONÇALVES ${ }^{3}$, L. R. B.; \\ M. V. P.ROCHA ${ }^{3}$ \\ ${ }^{1}$ Aluno do DEQ/UFC $\quad{ }^{2}$ Mestrando do DEQ/UFC $\quad{ }^{3}$ Professor da DEQ/UFC \\ Departamento de Engenharia Química - Universidade Federal Ceará \\ Endereço - Campus Universitário do Pici, Bloco 709, Fortaleza, CEP. CEP 60455-760, CE, \\ email: valponterocha@yahoo.com.br
}

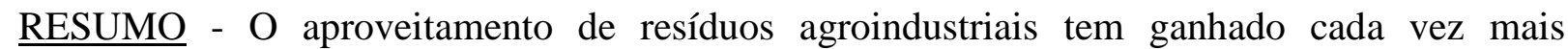
relevância, devido à necessidade de descarte desse material rejeitado da indústria e pode ser utilizado para a produção de outros produtos. O bagaço do caju (BC), resíduo obtido em larga escala no nordeste brasileiro, possui baixo valor agregado. Dessa forma, diversos estudos que visam incorporação de valor a essa matéria-prima são desenvolvidos. Nesse trabalho, investigou-se a produção de etanol e xilitol por uma linhagem de Candida tropicalis a partir do hidrolisado enzimático do BC pré-tratado. A hidrólise enzimática foi realizada a fim de se obter açúcares monoméricos fermentescíveis como, xilose e glicose, a partir das cadeias de hemicelulose e celulose presentes na biomassa do BC. Para potencializar a ação enzimática, testaram-se no BC in natura dois pré-tratamentos alcalinos: com hidroxido de sódio $(\mathrm{NaOH})$ e com peróxido de hidrogênio $\left(\mathrm{H}_{2} \mathrm{O}_{2}\right)$. Determinou-se que a maior concentração de açúcares foi obtida na hidrólise enzimática do $\mathrm{BC}$ pré-tratado com $\mathrm{H}_{2} \mathrm{O}_{2}$ pelas enzimas xilanase, complexo celulase e hemicelulase, com as respectivas cargas de 6,4 e $7 \mathrm{mg}$ de proteína por grama de BC pré-tratado. A levedura $C$. tropicalis produziu xilitol e etanol utilizando os carboidratos obtidos da hidrólise enzimática do bagaço de caju.

Palavras chave: enzimas, bagaço de caju, etanol, xilitol.

\section{INTRODUÇÃO}

O conceito de biorrefinaria foi desenvolvido para ser um modelo ideal de processamento integral da biomassa lignocelulósica (Modenbach e Nokes, 2013). Essa biomassa é um dos recursos renováveis mais disponíveis e representa uma materiaprima promissora de baixo custo, para a produção de biocombustíveis, bioenergia e biomoléculas de valor agregado (Boussarsar et al., 2009).

A biomassa lignocelulósica é composta principalmente de celulose, hemicelulose e lignina, estando esses constituintes distribuídos em diferentes quantidades percentuais, dependendo da espécie e condições de crescimento (Fengel e Wegener, 1989). 
A área ocupada com a cultura do caju no nordeste é de aproximadamente $700 \mathrm{mil}$ hectares, com uma produção de cerca de 1.260.000.000 quilos de pedúnculo. Somente 10 a $20 \%$ da produção anual do pedúnculo de caju no nordeste brasileiro é beneficiado, com a fabricação do suco integral $(70$ mil toneladas/ano), principal produto da industrialização do pedunculo do caju. Com um desperdício de 80 a $90 \%$ da sua produção, a cultura do caju apresenta um baixo nível de aproveitamento do pedúnculo (Embrapa, 2013).

Quando o pedúnculo é industrialmente processado para a produção do suco, $40 \%$ $(\mathrm{m} / \mathrm{m})$ de bagaço são produzidos e geralmente são rejeitados pelas indústrias locais (Correia et al., 2012). A composição média do bagaço de caju (BC) in natura é, aproximadamente, $20,56 \pm 2,19 \%$ de celulose, $10,17 \pm 0,79 \%$ de hemicelulose e 35,26 $\pm 0,90 \%$ de lignina (Correia et al., 2012; Rocha et al., 2010).

A utilização do bagaço de caju, para produzir biocombustíveis de segunda geração, requer pelo menos três etapas principais: (1) o pré-tratamento, a fim de abrir a estrutura da biomassa lignocelulósica, liberando a cadeia polímerica de açúcares das suas ligações com a lignina, (2) a hidrólise enzimática que quebra os polímeros de açúcar em seus monomeros fermentáveis, e (3) a fermentação do hidrolisados enzimático em xilitol, etanol ou em outros produtos (Fitzpatrick et al., 2010; Hendriks e Zeeman, 2009, Correia et al., 2012).

Como a estrutura complexa da biomassa lignocelulósica limita o acesso enzimático, faz-se necessário a realização de um pré-tratamento da fibra, a fim de melhorase a susceptividade da celulose e da hemicelulose a hidrólise enzimática (Boussarsar et al., 2009). As técnicas de prétratamento antes da hidrólise enzimática podem incluir métodos físicos (explosão de vapor, radiação, congelamento, etc) e métodos químicos (ácidos, álcalis solvente orgânico, etc) (Mood et al., 2013).

Após o pré-tratamento é realizado a hidrólise (ácida ou enzimática) para obter açúcares que serão utilizados na produção de outros produtos. $\mathrm{Na}$ hidrólise ácida há formação de produtos considerados tóxicos ao crescimento microbiano como, ácido acético e fórmico (Albuquerque et al., 2012; Rabelo, 2007). No entanto, na hidrólise enzimática não há formação destes inibidores (Modenbach e Nokes, 2013).

A hidrólise enzimática é tipicamente considerada o gargalo de toda a conversão no processo em termos de tempo e custo (Modenbach e Nokes, 2013) principalmente, pelo ainda alto custo de obtenção das enzimas, mesmo com os altos investimentos em pesquisas no ramo.

Nesse contexto, avaliaram-se dois prétratamentos alcalinos: com peróxido de hidrogênio $(4,3 \% \mathrm{v} / \mathrm{v})$ e hidróxido de sódio $(4 \% \mathrm{~m} / \mathrm{v})$ no BC in natura. E após estudou-se a hidrólise enzimática do bagaço de caju para obter açúcares fermentescíveis.

\section{MATERIAL E MÉTODOS}

\section{Pré-tratamento do Bagaço de Caju}

$\mathrm{O}$ bagaço de caju in natura, cedido pela Indústria Sucos do Brasil S/A, foi submetido a dois pré-tratamentos, isoladamente. Parte sofreu tratamento por peróxido de hidrogênio $4,3 \%$ (v/v) e pH 11,5, ajustado com $\mathrm{NaOH} 3$ $\mathrm{M}$ a uma porcentagem de sólidos de $4 \%(\mathrm{~m} / \mathrm{v})$ a $250 \mathrm{rpm}, 35^{\circ} \mathrm{C}$ por $6 \mathrm{~h}$. A outra parte do bagaço in natura sofreu tratamento por uma solução $\mathrm{NaOH} 4 \%(\mathrm{~m} / \mathrm{v})$ a $121{ }^{\circ} \mathrm{C}$ por $30 \mathrm{~min}$. Separou-se ao final do processo, por filtração à vácuo, o sólido que foi submetido a lavagens, com água destilada, para total remoção dos álcalis. Em seguida, foi seco em estufa a $50{ }^{\circ} \mathrm{C}$ por $24 \mathrm{~h}$ e selecionado entre 0,17 a $0,84 \mathrm{~mm}$. Os sólidos resultantes foram caracterizados.

\section{Caracterização do Bagaço de Caju pré- tratado}

O bagaço de caju in natura após os dois pré-tratamentos foi caracterizado quanto à sua composição de celulose, hemicelulose e lignina segundo a metodologia de Gouveia et al. (2009), validada para a caracterização de bagaço de cana-de-açúcar.

\section{Hidrólise Enzimática do Substrato Pré- tratado}


A hidrólise foi realizada em tampão citrato de sódio $100 \mathrm{mM}$, fixando-se a quantidade de substrato em $3 \mathrm{~g}$ e o volume reacional em $50 \mathrm{ml}$. Os ensaios foram conduzidos em frascos Erlenmeyer de $250 \mathrm{~mL}$ agitação de $150 \mathrm{rpm}$, a $45{ }^{\circ} \mathrm{C}$ por $48 \mathrm{~h}$. As enzimas xilanase, complexo celulase e hemicelulase foram utilizadas com as respectivas cargas de 6,4 e $7 \mathrm{mg}$ de proteína por grama de BC pré-tratado (Gomes et al., 2013). A cada 24 h, retirou-se uma alíquota da mistura para determinação de açúcares.

\section{Produção de Xilitol e Etanol por Candida tropicalis}

Uma linhagem de Candida. Tropicalis (GPBIO) utilizada nesse estudo, foi estocada em Agar YEPD inclinado (extrato de levedura, 10 g. $\mathrm{L}^{-1}$; peptona, 20 g. $\mathrm{L}^{-1}$; dextrose, 20 g. $\mathrm{L}^{-1}$, e ágar, 20 g. $\left.\mathrm{L}^{-1}\right)$. Para o preparo do inóculo, o micro-organismo foi cultivado em caldo YEPD por 24_h, em seguida centrifugou-se a quantidade de meio correspondente a 1,0 g. $\mathrm{L}^{-1}$ e inoculou-se o precipitado celular no hidrolisado. $\mathrm{O}$ hidrolisado enzimático obtido da hidrólise do $\mathrm{BC}$ pré-tratado por $\mathrm{H}_{2} \mathrm{O}_{2}$ não recebeu nenhuma suplementação nutricional e foi esterilizado. A fermentação foi conduzida em agitador orbital a $30{ }^{\circ} \mathrm{C}$ e $200 \mathrm{rpm}$ por 96 h.

\section{Determinação da concentração de glicose, xilose, xilitol e etanol}

Os açúcares (glicose e xilose) e os produtos (xilitol e etanol) foram analisados por cromatografia de alta performance (CLAE), utilizando um sistema CLAE Waters (Waters, Milford, MA, EUA) equipado com um índice de refação Waters 2414 detector. As concentrações de açúcares foram analisadas utilizando coluna Aminex HPX-87P, usando como efluente água ultrapura a uma taxa de fluxo de $0,5 \mathrm{ml} \cdot \mathrm{min}^{-1}$.

\section{RESULTADOS E DISCUSSÃO}

Após realizar os pré-tratamentos no bagaço de caju caracterizou-se o material prétratado. Os resultados da caracterização estão resumidos na Tabela 1 . O pré-tratamento com $\mathrm{H}_{2} \mathrm{O}_{2}(4,3 \%$ v/v) resultou em uma fibra com a seguinte composição 42,91 $\pm 2,68 \%$ de celulose, $16,20 \pm 1,13 \%$ de hemicelulose e $8,17 \pm 2,68 \%$ de lignina. Os valores obtidos neste trabalho são bem semelhantes aos valores reportados por Correia et al., (2012).

Já o pré-tratamento com $\mathrm{NaOH}(4 \%$ $\mathrm{m} / \mathrm{v}$ ) resultou em uma fibra com a seguinte composição16,21 $\pm 2,04 \%$ de celulose, 11,48 $\pm 1,53 \%$ de hemicelulose e $30,27 \pm 0,27 \%$ de lignina.

Tabela 1 - Caracterização do BC in natura e após o pré-tratamento com $\mathrm{H}_{2} \mathrm{O}_{2}$ e $\mathrm{NaOH}$.

\begin{tabular}{lcllll}
\hline $\begin{array}{l}\text { Matéria } \\
\text {-prima }\end{array}$ & $\begin{array}{c}\text { Extraíveis } \\
(\%)\end{array}$ & $\begin{array}{l}\text { Celulose } \\
(\%)\end{array}$ & $\begin{array}{l}\text { Hemicelulose } \\
(\%)\end{array}$ & $\begin{array}{l}\text { Lignina } \\
(\%)\end{array}$ & $\begin{array}{l}\text { Cinzas } \\
(\%)\end{array}$ \\
\hline In & 7,79 & 20,56 & 10,17 & 35,26 & 1,62 \\
natura & $\pm 0,60$ & $\pm 2,19$ & $\pm 0,79$ & $\pm 0,90$ & $\pm 0,07$ \\
& & & & & \\
$\mathrm{H}_{2} \mathrm{O}_{2}$ & 5,08 & 42,91 & 16,20 & 8,17 & 16,72 \\
$4,3 \%$ & $\pm 0,33$ & $\pm 2,68$ & $\pm 1,13$ & $\pm 2,68$ & $\pm 1,09$ \\
& & & & & \\
$\mathrm{NaOH}$ & 5,76 & 16,21 & 11,48 & 30,27 & 11,13 \\
$4 \%$ & $\pm 0,34$ & $\pm 2,04$ & $\pm 1,53$ & $\pm 0,27$ & $\pm 0,05$ \\
& & & & & \\
\hline
\end{tabular}

Os dois pré-tratamentos alcalinos, com $\mathrm{H}_{2} \mathrm{O}_{2}$ e $\mathrm{NaOH}$, degradaram a cadeia de lignina presente no $\mathrm{BC}$, entretanto o pré-tratamento com $\mathrm{H}_{2} \mathrm{O}_{2}$ mostrou-se mais eficiente na remoção do polímero, em relação ao outro testado, pois o $\mathrm{BC}$ pré-tratado com $\mathrm{NaOH}$ apresentou uma maior porcentagem de lignina $(30,27 \pm 0,27 \%)$ em relação ao BC pré-tratado por $\mathrm{H}_{2} \mathrm{O}_{2}(8,17 \pm 2,68 \%)$.

$\mathrm{O}$ melhor resultado do pré-tratamento realizado com $\mathrm{H}_{2} \mathrm{O}_{2}$ explica-se pelo fato do principal alvo do ataque químico na reação ser a lignina e não as demais cadeias (Rabelo, 2007).

A fração sólida, resultante dos prétratamentos realizados, que apresentou maior valor percentual de hemicelulose (16,20 \pm $1,13 \%)$, cadeia de interesse no presente trabalho por ser precursora do açúcar de interesse que é a xilose, foi aquela exposta a ação do $\mathrm{H}_{2} \mathrm{O}_{2} 4,3 \%$ (v/v).

O tratamento alcalino é reportado na literatura pela sua capacidade de solubilizar a lignina, um constituinte da fibra que dificulta a ação enzimática impedindo que o sítio ativo da enzima se ligue ao substrato (Alvira et al., 2010). E os pré-tratamentos oxidativos têm sido usados para dissolver os componentes da matriz ligocelulósica e acelerar a hidrólise 
enzimática (Rabelo, 2007), o que torna o $\mathrm{H}_{2} \mathrm{O}_{2}$ um pré-tratamento eficiente na deslignificação da biomassa é a adição do $\mathrm{NaOH}$, durante a correção do $\mathrm{pH}$ da solução, que provoca a formação do ânion hidroperóxido $\left(\mathrm{HOO}^{-}\right)$ principal espécie ativa do peróxido (Rabelo, 2007). Em condições alcalinas, o peróxido é instável e se decompõe em radicais hidroxil $\left(\mathrm{OH}^{-}\right)$e superóxido $\left(\mathrm{O}_{2}^{-}\right)$que oxidam a lignina, quebrando algumas ligações.

$\mathrm{O}$ tratamento com $\mathrm{NaOH}$, em comparação com outras tecnologias de prétratamento, utiliza temperaturas mais baixas e apresenta uma maior recuperação de açúcares, no entanto o tratamento com uma grande quantidade de licor negro torna-se um desafio com $\mathrm{NaOH}$ (Yu et al, 2013). Os maiores inconvenientes do método são a necessidade de neutralização da suspensão resultante do pré-tratamento (Mood et al., 2013).

Após o pré-tratamento, realizou-se a hidrólise enzimática nos sólidos pré-tratados e os resultados da hidrólise enzimática estão apresentados nas Figuras 1 e 2. O maior rendimento de glicose $\left(19,92 \pm 0,63\right.$ g. $\left.\mathrm{L}^{-1}\right)$ e de xilose $\left(8,97 \pm 0,64 \mathrm{~g} . \mathrm{L}^{-1}\right)$ foram obtidos em, respectivamente, $24 \mathrm{~h}$ e $48 \mathrm{~h}$ de hidrólise para o $\mathrm{BC}$ pré-tratado por $\mathrm{H}_{2} \mathrm{O}_{2}$. Já para o $\mathrm{BC}$ prétratado por $\mathrm{NaOH}$, as maiores concentrações de glicose e xilose foram de 12,64 $\pm 0,50$ g. $\mathrm{L}^{-1}$ e 4,87 $\pm 0,20 \mathrm{~g} . \mathrm{L}^{-1}$, respectivamente, com 72_h de hidrólise. Observou-se ainda que a xilose só foi liberada após 24 horas de hidrólise, supostamente pela baixa carga de enzimas utilizadas nos experimentos.

$\mathrm{O}$ substrato pré-tratado por $\mathrm{H}_{2} \mathrm{O}_{2}$ resultou em uma maior concentração de açúcares na etapa de hidrólise enzimática, possivelmente, pela remoção da lignina ter sido mais efetiva com este pré-tratamento quando comparado ao outro realizado.

A ação das três enzimas foi importante na hidrólise enzimática do $\mathrm{BC}$, pois tornou mais efetiva a quebra dos polímeros, enquanto que a maior quantidade usada de hemicelulase ajudou a direcionar a hidrólise para obtenção do açúcar de interesse que é a xilose.

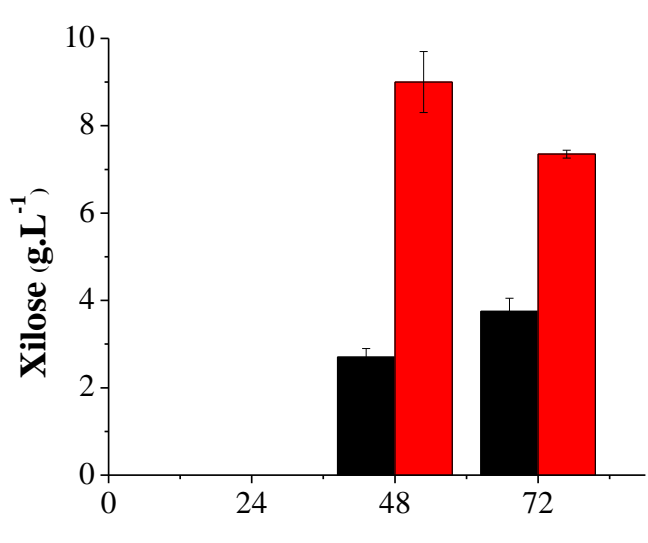

Tempo (h)

Figura 1- Concentração de xilose obtida na hidrólise enzimática a $45^{\circ} \mathrm{C}$ e $150 \mathrm{rpm}$ do $\mathrm{BC}$ pré-tratado com $\mathrm{NaOH}(\square)$ e com $\mathrm{H}_{2} \mathrm{O}_{2}(\square)$.

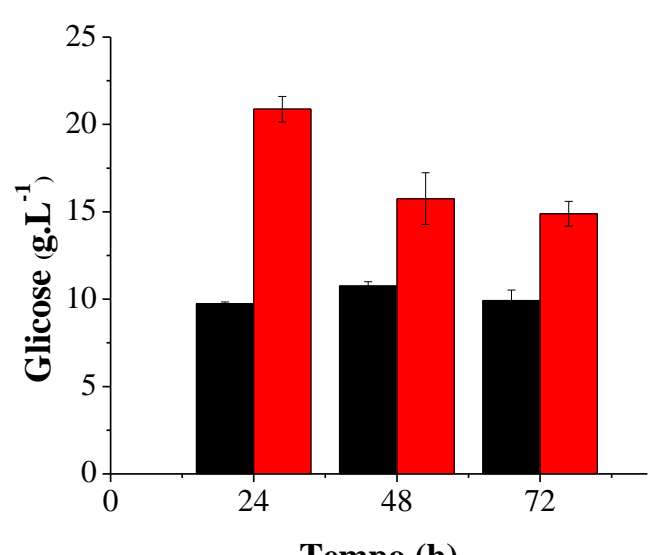

Tempo (h)

Figura 2 - Concentração de glicose obtida na hidrólise enzimática a $45^{\circ} \mathrm{C}$ e $150 \mathrm{rpm}$ do $\mathrm{BC}$ pré-tratado com $\mathrm{NaOH}(\mathbf{\square})$ e com $\mathrm{H}_{2} \mathrm{O}_{2}(\square)$.

Mesmo que a hemicelulose seja um polissacarídeo complexo, sua degradação enzimática é bem elucidada. Ocorre, de acordo com Aro (2004), uma ação combinada de endo-enzimas clivando internamente a cadeia principal e de exo-enzimas que liberam açúcares monoméricos e enzimas auxiliares que quebram lateralmente a cadeia de polímeros ou oligossacarídeos, levando à liberação de vários mono e dissacarídeos. Já a degradação da celulose ocorre apartir das celulases que são um complexo de enzimas constituídos de três enzimas as endoglucanases (EG), exoglucanases e $\beta$-glicosidase. As endoglucanases atacam aleatoriamente a cadeia de celulose para formar glicose, celobiose e celotriose. As celobiohidrolases (exoglucanases) fracionam a cadeia em dímeros de glicose (celobiose). Outra enzima, 
$\beta$-glicosidase, possui função de conversão da molécula de celobiose em duas moléculas de glicose (Correia et al., 2012; Keshwani, 2009).

Como o hidrolisado do bagaço de caju pré-tratado com peróxido de hidrogênio apresentou maiores concentrações de xilose e glicose, selecionou-se esse líquido para avaliar a produção de xilitol e etanol.

A levedura Candida tropicalis foi capaz de metabolizar os carboidratos e produzir 6,8 g/L de xilitol e 6,0 g/L de etanol com 96 h de cultivo. Então, o hidrolisado enzimático obtido do bagaço de caju prétratado com $\mathrm{H}_{2} \mathrm{O}_{2}$ pode ser utilizado para produzir xilitol e etanol.

\section{CONCLUSÃO}

$\mathrm{O}$ pré-tratamento que resultou em maior redução da lignina $(8,17 \pm 2,68 \%)$ foi aquele no qual o bagaço de caju sofreu ação do peróxido de hidrogênio $(4,3 \% \mathrm{~m} / \mathrm{v})$ e no mesmo obtevese a maior concentração de açúcares após a hidrólise enzimática, com concentrações de glicose e xilose de, respectivamente, 19,92 \pm 0,63 g. $\mathrm{L}^{-1}$ e $8,97 \pm 0,64$ g. $\mathrm{L}^{-1}$. A levedura $C$. tropicalis produziu xilitol e etanol utilizando os carboidratos obtidos da hidrólise enzimática do bagaço de caju.

\section{REFERÊNCIAS}

ALBUQUERQUE, T. L., GOMES, S. D. L., JUNIOR, J. E. M., GONÇALVES, L. R. B., SILVA JR, J, I., ROCHA M, V, P. (2013), “Avaliação da influência de tratamentos de destoxificação do hidrolisado de bagaço de caju na produção de xilitol por Candida tropicalis". In: Simpósio Nacional de Bioprocessos SINAFERM, Foz de Iguaçu.

ALVIRA, P., TOMÁS-PEJÓ, E., BALLESTEROS, M., NEGRO, M. (2010), Pretreatment Technologies for an efficient bioethanol production process based on enzymatic hydrolysis: A review. Bioresource Technology, 101, 4851-4861.

ARO, N., PAKULA, T., PENTTILA, M. (2004), Transcriptional regulation of plant cell wall degradation by filamentous fungi. FEMS Microbiology Reviews, 29, 719-739.

BOUSSARSAR, H., ROGÉ, B., MATHLOUTHI, M. (2009), Optimization of sugarcane bagasse conversion by hydrothermal treatment for the recovery of xylose. Bioresource Technology, 100, 6537-6542.

CORREIA, J., ROCHA, M., GONÇALVES, L. (2012), "Efeito da combinação de enzimas na hidrólise enzimática do bagaço de caju pré-tratado com peróxido de hidrogênio para produção de etanol". In: Congresso Brasileiro de Engenharia Química COBEQ, Búzios.

EMBRAPA site: http://www.agencia.cnptia.embrapa.br/ges tor/caju/arvore/CONT000fr3sbpu402wyiv 80084arlaeog5af.html acesso em novembro de 2013. Autor : Raimundo Marcelino da Silva Neto.

FENGEL, D., WEGENER, G. (1989), Wood Chemistry, Ultrastructure and Reactions, $1^{\text {st }}$ ed., Walter de Gruyter: Berlin, p. 106109.

FITZPATRICK, M., CHAMPAGNE, P., CUNNINGHAM, M. F., WHITNEY, R. A. (2010), A biorefinery processing perspective: treatment of lignocellulosic materials for the production of valueadded products. Bioresource Technology, 101, 8915-8922.

GOMES, S. D. L., ALBUQUERQUE, T. L., JUNIOR, J. E. M., GONÇALVES, L. R. B., ROCHA, V. P. (2013), "Estudo da hidrólise enzimática do bagaço de caju visando a obtenção de xilose". In: Simpósio Nacional de Bioprocessos SINAFERM, Foz de Iguaçu.

GOUVEIA, E. R., DO NASCIMENTO R, T., SOUTO-MAIOR, A. M., ROCHA, G. J. M. (2009), Validação de metodologia para a caracterização química de bagaço de canade-açúcar. Química Nova, 6, 32, 1500-1503. 
HENDRIKS, A. T., ZEEMAN, G. (2009), Pretreatments to enhance the digestibility of lignocellulosic biomass. Bioresource Technology, 100, 10-18.

KESHWANI, D. R. (2009), Microwave pretreatment of switchgrass for bioethanol production. Tese (Doutorado). Universidade Estadual da Carolina do Norte, Carolina do Norte, Estados Unidos da América.

MODENBACH, A, A., NOKES, S, E. (2013), Enzymatic hydrolysis of biomass at hightsolids loadings- A review. Biomass and Bioenergy, 56, 526-544.

MOOD, S, H., GOLFESHAN, A, H., TABATABAEI, M., JOUZANI, G, S., NAJAFI, G, H., GHOLAMI, M., ARDJMAND, M. (2013), Lignocellulosic biomass to bioethanol, a comprehensive review with a focus on pretreatment. Renewable and Sustainable Energy Reviews, 27, 77-93.

RABELO, S.C. (2007), Avaliação de desempenho do pré-tratamento com peróxido de hidrogênio alcalino para hidrólise enzimática de bagaço de canade-açúcar. Dissertação (mestrado) Universidade Estadual de Campinas, área de concentração: Desenvolvimento de processos químicos, Campinas/SP, Brasil, 150 p.

ROCHA, M. V. P. (2010), Produção de Bioetanol a partir de Pedúnculo de caju (Anacardium occidentale L.) por Fermentação Submersa. Tese de Doutorado -UFRN, Programa de Pós Graduação em Engenharia Química PPGEQ, Área de Concentração: Engenharia de Processos, Natal/RN, Brasil, 162p.

YU, Q., ZHUANG, X., YUAN, Z., QI, W., WANG, W., WANG, Q., TAN, X. (2013), Pretreatment of sugarcane bagasse with liquid hot water and aqueous ammonia. Bioresource Technology, 144, 210-215. 